\title{
La trayectoria constitucional boliviana: entre transformación y desafío jurídico. El estado metodológico de la cuestión ${ }^{* *}$
}

\section{Bolivian Constitutional Path: Between Transformation and Legal Challenge. The Methodological State of Affairs}

RESUMEN

Este trabajo intenta ofrecer una breve respuesta a los cambios ocurridos en Bolivia tras la aprobación de la Constitución de 2009. Para hacerlo es necesario indicar algunos elementos que identifican un verdadero cambio generacional que ha llevado a hablar de neoconstitucionalismo, y sobre todo, cómo el país ha abordado la cuestión de los pueblos indígenas y de sus sistemas de justicia.

PALABRAS CLAVE

Neoconstitucionalismo, Constitución Política Boliviana, justicia indígena, pluralismo político.

\section{ABSTRACT}

This paper attempts to give a brief response to the changes made in the Bolivian Plurinational State after the aproval Constitution in 2009. To do this it is neccesary to understand how Bolivia is facing a generational change that has led to talk about neo-constitutionalism, and most of all how the country is constitutionally confronting the issue of indigenous people and their justice system.

* Doctor internacional en Derecho y Ciencias Políticas por la Universidad Pública Pablo de Olavide de Sevilla y Premio Extraordinario de Doctorado. Profesor de Derecho Constitucional en la misma Universidad, acreditado Profesor Contratado Doctor (ANECA). Investigador del Centro Euro-Árabe de Estudios Jurídicos Avanzados; coordinador de Relaciones Internacionales y Movilidad de la Facultad de Derecho de la Universidad Pablo de Olavide de Sevilla. Profesor visitante de la Universidad de Ibagué, Colombia, donde imparte Teoría del Estado. Investigador del Grupo Zoon Politikon de la misma Universidad. Contacto: gves1@upo.es

Recibido el 25 de febrero de 2016, aprobado el 1. ${ }^{\circ}$ de octubre de 2016.

Para citar el artículo: G. Vestri. La trayectoria constitucional boliviana: entre transformación y desafío jurídico. El estado metodológico de la cuestión. Derecho del Estado n. ${ }^{\circ}$ 37, Universidad Externado de Colombia, julio-diciembre de 2016, pp. 213-228. DOI: http://dx.doi.org/10.18601/01229893.n37.07 
KEYSWORDS

Neoconstitutionalism, Constitution of Bolivia, indigenous justice, legal pluralism.

SUMARIO

Introducción. I. ¿El neoconstitucionalismo como substituto del constitucionalismo clásico? II. La transición del pluralismo jurídico al pluralismo jurisdiccional. III. La línea de demarcación de los límites de la justicia indígena. A modo de conclusión.

\section{INTRODUCCIÓN}

El presente trabajo tiene el afán de valorar los elementos que en el año 2009 llevaron a la aprobación de la Constitución Política del Estado Plurinacional de Bolivia (en adelante, СРв). Es sabido que existen sectores de la Carta que desarrollaron un papel significativo en el reconocimiento de derechos hasta aquel entonces desconocidos y que, en puntuales ocasiones, parecieron populistas, si bien fueron necesarios para dar un impulso innovador a la génesis de la nueva CPB.

En primer lugar, entonces, es nuestro deber identificar los posibles criterios que ubican los conceptos de constitucionalismo y neoconstitucionalismo, finalmente pilares sobre los cuales Bolivia ha creado su política interior. Cabe destacar que en el Estado Plurinacional de Bolivia, sobre todo a partir de la llegada de Evo Morales, se ha implantado un socialismo comunitario que, a diferencia de otras experiencias -Venezuela o Ecuador, $v . g r$.-, se queda fuera de los discursos oficiales aunque identifica una ruptura con el capitalismo que, según esta lógica, tuvo efectos catastróficos sobre la igualdad, el empleo y la naturaleza ${ }^{1}$. Correctamente, en esta óptica, Viciano Pastor, al hablar de dicha cuestión tomando como ejemplo el caso de Venezuela, acierta al afirmar: "Es ahora cuando se está en disposición de definir cuál va a ser el rumbo final del proceso de cambio político-social en Venezuela. De lo que ahora se haga dependerá que mucha gente, dentro y fuera de Venezuela, se mantenga unida e identificada con el mismo o, por el contrario, que entienda que se ha tratado de una nueva oportunidad perdida por la izquierda emancipadora, democrática y socialista"².

1 En este sentido ver Kats, C. La sorpresa de Bolivia. En Nómadas. Revista Crítica de Ciencias Sociales y Jurídicas, n. $^{\circ}$ 44, 2014.

2 Viciano Pastor, R. Una análisis sobre la propuesta de reforma constitucional de Venezuela en 2007. En Cuadernos de Trabajos Hengoa, n. ${ }^{\circ}$ 44, 2008, 13. 
En este contexto resulta entonces interesante preguntarnos cuáles son los elementos que caracterizan el constitucionalismo y cuáles los que identifican la síntesis del "neo"constitucionalismo. Esta visión, que intentaré profundizar y que a priori podría resultar sencilla, en realidad esconde lo que Miguel Carbonell define como un laberinto, o en otros términos, un enredo desde el punto de vista axiológico y doctrinal ${ }^{3}$.

La CРB es tan nueva (por lo menos en términos de fechas) que su contenido parece romper con los principios constitucionales tradicionales procedentes de la Constitución francesa o italiana de 1948 o de la Ley Fundamental alemana de 1949, esto es, lo que conocemos como el constitucionalismo clásico. Esta afirmación encuentra su sentido, por ejemplo, en el mismo catálogo de los derechos fundamentales. Algunos de ellos ${ }^{4}$, reconocidos como fundamentales en la $\mathrm{CPB}$, son apenas considerados como principios rectores o derechos sociales en el constitucionalismo clásico.

En este mismo sentido, en 2009, año de aprobación de la СРB, el constitucionalismo europeo tuvo que enfrentarse, una vez más, al desafío producido por las novedosas y a veces no compartidas constituciones latinoamericanas. Es cierto que este reto empezó con la Constitución Política de Colombia de 1991, y sin embargo parece que la СРв afianza una nueva visión del constitucionalismo latinoamericano. Los esquemas constitucionales tradicionales parecían haber perdido el papel que siempre tuvieron, y parecía surgir una nueva época constitucional inspiradora de una renovada manera de ver la sociedad.

Sin embargo y en mi visión, esto no significa que el constitucionalismo latinoamericano y en particular el boliviano represente la salvación del Estado social, aunque, eso sí, debe simbolizar el impulso para la doctrina constitucional de ponerse en duda frente a una manera de entender la Constitución que parece distanciarse de normas de principios axiológicos y favorecer el asentamiento del derecho basado en las exigencias cotidianas de los ciudadanos.

Tras esto y a la luz del contenido de la CPB, es necesario apreciar aquellos criterios de pluralismo jurídico que en Bolivia, quizá más que en otros países latinoamericanos, encuentran una aplicación puntual por lo menos desde el punto de vista teórico. En este sentido bastaría con leer el capítulo IV de la СРв para entender el concepto de pluralismo jurídico; sin embargo, a mi entender, los constituyentes bolivianos omitieron, entiendo que de forma involuntaria, que el verdadero desafío estaba y está en el reconocimiento del pluralismo jurisdiccional. En otras palabras, ¿pueden coexistir el pluralismo jurisdiccional y la justicia ordinaria y centralizada del Estado? ¿Existe una línea insuperable entre la justicia indígena-campesina y la justicia ordinaria?

3 Carbonell SÁnchez, M. El neoconstitucionalismo en su laberinto. Teoría del neoconstitucionalismo: ensayos escogidos, 2007.

4 Ver el derecho a la vivienda digna. 
I. ¿EL NEOCONSTITUCIONALISMO COMO SUBSTITUTO

DEL CONSTITUCIONALISMO CLÁSICO?

La СРв es uno de los ejemplos jurídicos que manifiesta la necesidad de establecer patrones claros sobre lo que significa constitucionalismo y neoconstitucionalismo. La Carta encuentra su génesis exactamente en este cúmulo de viejas tendencias constitucionales que a la par se fusionan con nuevas ideas. En algunos casos la norma es profundamente novedosa (véase el caso del reconocimiento de la plurinacionalidad y, entonces, de los pueblos indígenas que ancestralmente habitaban el país), aunque al mismo tiempo resulta radicada en la mera literalidad formal de las normas constitucionales que finalmente impiden el desarrollo del principio de efectividad (es el caso del derecho a la vivienda digna que está previsto entre los derechos fundamentalísimos de la Constitución).

Si tuviera que definir los elementos del neoconstitucionalismo, probablemente no cometería ningún error en aceptar las tesis según la cual este es una expresión que resume una serie de nuevas tendencias conceptuales, como por ejemplo la búsqueda de mayor democracia, el replanteamiento del poder y de los órganos del Estado, la diferente relación entre el derecho interno y el derecho internacional, el fundamental papel de los derechos humanos y de la justicia constitucional, además del establecimiento de una responsabilidad de interpretación judicial ${ }^{5}$. También, entre otras, cabe compartir la visión de Zagrebelsky cuando afirma que "el constitucionalismo moderno es una idea de derecho que parece exigir una profunda renovación de numerosas concepciones jurídicas que hoy operan en la práctica" ${ }^{6}$. El neoconstitucionalismo podría representar esta renovación. Por su parte, Ratti plantea un neoconstitucionalismo positivo (que encarna el cambio de paradigma) y uno negativo (que sería la negación del positivismo) y señala que hoy en día "la expresión neoconstitucionalismo" es sumamente ambigua: la cultura contemporánea la usa para denotar cosas tan heterogéneas como una forma de Estado, una política de activismo judicial, una reconstrucción teórica de los sistemas jurídicos contemporáneos, una metodología jurídica y una adhesión ideológica al derecho ${ }^{7}$.

En este orden de ideas, cabe destacar que la partícula "neo" encarna la hipótesis de que exista algo nuevo que prevalece sobre lo obsoleto. Sin embargo, el hecho de que existan elementos novedosos no significa automáticamente

5 En este sentido ver Rolla Giancarlo, L'evoluzione del costituzionalismo in America Latina e l'originalità delle esperienze di giustizia costituzionale, disponible en: http://ojs .uniurb. it/index.php/studi-A/article/download/109/101

6 Zagrebelsky, G. Il diritto mitte. Legge, diritti, giustizia. Torino: Einaudi, 1992; trad. esp., El derecho dúctil. Marina Gascón, trad. Madrid: Trotta, 4. ${ }^{\text {a }}$ ed., 2002, 9.

7 RatTi, G. B. Neoconstitucionalismo positivo y neoconstitucionalismo negativo, Ius Humani. En Revista de Derecho, vol. 4, 2014, 227-261. 
excluir y desconocer los principios clásicos del constitucionalismo. En este sentido es entonces necesario emprender una relectura de la visión bipartisan, en donde por un lado tenemos al constitucionalismo clásico, que parece haber fracasado en la época moderna, y por el otro tenemos el neoconstitucionalismo, que se entiende como el remedio a las frustraciones político-constitucionales de un país. Creo que la verdad sobre este tema está en medio, y que el equilibrio y la integración entre las dos tesis es el verdadero punto focal. Es por esto que prefiero hablar de constitucionalismo clásico, entendido como la ciencia jurídica que establece teorías y modelos de base útiles para un desarrollo normativo posterior, y de constitucionalismo social, en donde la Constitución debería tener la capacidad de limitar las tendencias expansivas de la mayoría de los sistemas políticos homogeneizados y de nivel mundial. En este sentido, sería preciso retomar en cierta medida el concepto histórico de soberanía, según el cual los Estados no deberían aceptar injerencias en su política interior perpetradas, por un lado, por países más poderosos y entregados al neocapitalismo, y, por el otro, por corporaciones y multinacionales que se mueven de acuerdo con lógicas mercantilistas. Como apunta de Vega García, esta situación conlleva que "el espectacular ensanchamiento de los espacios económicos y sociales, no se ha visto acompañado de una similar amplitud de los espacios políticos" ${ }^{\prime}$. Y más, utilizando las palabras de Rolla, al hablar de la relación entre constitucionalismo y neoconstitucionalismo, "los trazos esenciales de tal cambio pueden ser individualizados esencialmente en tres elementos: la naturaleza del proceso constituyente, la afirmación de una idea diferente de Constitución y el perfeccionamiento de las técnicas de garantía de los derechos fundamentales" .

La doctrina es unánime en reconocer que los orígenes del constitucionalismo clásico hasta el siglo de las Luces se pueden esquematizar con los eventos de interés histórico e institucional. El siglo en cuestión fue identificado con una reorientación para la historia de la humanidad, tras las revoluciones de la burguesía y los principios de las nuevas declaraciones de derechos que se materializaron en constituciones ${ }^{10}$. Las primeras constituciones (entre otras, la Constitución americana de 1787 o la francesa de 1791) y sin dudas las actuales se basaron en el principio de libertad así como en la apreciación del individuo humano. Esta libertad se expresa a través de las libertades individuales y las

8 De Vega García, P. Mundialización y derecho constitucional: la crisis del principio democrático en el constitucionalismo actual. En Revista de Estudios Políticos (nueva época), n. ${ }^{\circ} 100$, abril-junio, 1998,13 .

9 Rolla, G. L'evoluzione del costituzionalismo in America Latina e l'originalità delle esperienze di giustizia costituzionale, disponible en: http://ojs.uniurb.it/index.php/studi-A/article/ download/109/101

10 Entre otros, ver Alvarado, A. Del constitucionalismo liberal al constitucionalismo social. Teoría y práctica. Sucre: Corte Suprema de Justicia de la Nación, Editorial Judicial, 1994, 73-74. 
libertades de la vida pública. En esta situación y "paralelamente a la redacción de las normas de derecho se compilaron las primeras constituciones modernas deliberadas por el pueblo o por sus representantes" el individuo y el necesario reconocimiento de la igualdad sobre cualquier necesidad, aunque el Estado mantenga una posición de fuerza y supremacía ${ }^{12}$.

Según diferentes autores, la siguiente senda consiste en establecer la diferencia entre la sociedad civil y el Estado que puede dar lugar al llamado constitucionalismo liberal ${ }^{13}$. Dentro de este conceptualismo axiológico vale la pena mencionar también lo que Noguera Fernández identifica como constitucionalismo multicultural latinoamericano, es decir, un constitucionalismo de tercera generación. Tomando en cuenta principalmente los casos boliviano y colombiano, el autor en cita identifica tres ejes fundamentales: 1) la reordenación del espacio público participativo; 2) la construcción de un ejercicio de comprensión, interpretación y práctica jurídica pluralista que saque al derecho del restringido ámbito de actuación de profesionales y operadores jurídicos, y 3) la aceptación como fuente generadora de derecho de nuevas prácticas sociales infra-estatales propias de los movimientos sociales ${ }^{14}$. Se percibe entonces un cambio. Esta metamorfosis no puede definirse radical, de hecho inicia cuando las sociedades afirman la democracia social, entendida como desarrollo de la democracia política a través del constitucionalismo social y que finalmente no desconoce los principios básicos del constitucionalismo clásico sino más bien los fortalece y los enriquece ${ }^{15}$. El constitucionalismo social establece y reconoce los "derechos sociales en cuanto tales [...] frente a la realidad y a la existencia social de los hombres. Los derechos individuales no son y no pueden ser absolutos y excluyentes" ${ }^{16}$.

Finalmente, entonces, los elementos del constitucionalismo social son: la estabilidad de los derechos individuales y el reconocimiento de los derechos colectivos y comunitarios. En otros términos, se trata de retomar conciencia sobre el contenido de aquel derecho natural de los hombres que a veces con demasiada facilidad tenemos la tendencia a olvidar. Según la idea de Pascucci

11 Pizzorusso, A. Il patrimonio costituzionale europeo. Bolonia: Il Mulino, 2002, 37.

12 En este sentido, ver Fioravanti, M. Constitucionalismo. Experiencias históricas y tendencias actuales. Madrid: Trotta, 2014.

13 Entre otros, ver ATTARD BELLIDO, M. E. La última generación del constitucionalismo: el pluralismo descolonizador intercultural y sus alcances en el Estado Plurinacional de Bolivia. En Revista Lex Social, vol. 2, n. ${ }^{\circ}$ 2, julio-diciembre, 2002, 141-143, y VALENCIA VEGA, A. Desarrollo del constitucionalismo. Colección Ayer y Hoy. La Paz: Juventud, 2002, 117.

14 Noguera Fernández, A. ¿De qué hablamos cuando hablamos de constitucionalismo multicultural? En Anuario de la Facultad de Derecho, vol. xvIII, 2010, 92.

15 Ver Díaz Gamboa, L. B. Constitucionalismo social: hacia un nuevo Estado social, democrático de derecho. Instituto Sindical Mario Cano, 2001, 28.

16 Valencia Vega. Desarrollo del constitucionalismo, cit., 216. 
de Ponte, se trata de retomar aquellos derechos subjetivos que las personas deben tener por el mero hecho de ser hombres ${ }^{17}$.

Desde otro punto de vista, este es el modelo sobre el que se basan los derechos humanos modernos y que se ve plasmado en diferentes tratados y acuerdos, y que en el caso que nos atañe se recogen en el Pacto Internacional de Derechos Económicos, Sociales y Culturales (PIDESC) ${ }^{18}$. Es cierto que la cuestión de los derechos sociales en Latinoamérica es más complicada de lo que aparece, sin embargo, la mayoría de las constituciones, y en particular la de Bolivia, están compuestas por una lista bastante extensa de derechos sociales; aunque es de reconocer que en el caso boliviano este resultado parece ser la aceptación forzada por parte de las fuerzas políticas dominantes que tuvieron que hacer frente a la elevada desafección política de la ciudadanía, tanto que en algunos casos se vieron forzadas a asumir un compromiso social frente al pueblo que a veces ha resultado demasiado utópico ${ }^{19}$. Dice Rivera, ex magistrado del Tribunal Constitucional de Bolivia, que la Constitución Política del Estado Plurinacional de Bolivia es el resultado de las exigencias y las aspiraciones de diferentes sectores sociales que en el pasado se vieron constreñidos y alejados de la organización estatal ${ }^{20}$.

\section{LA TRANSICIÓN DEL PLURALISMO JURÍDICO}

AL PLURALISMO JURISDICCIONAL

El Preámbulo de la CPB semánticamente esclarece cualquier duda en relación a las exigencias legales y jurídicas del texto. No se puede negar que el pueblo boliviano, desde siempre, es de composición plural y que a eso le corresponde o debería corresponder el reconocimiento del pluralismo jurídico y jurisdiccional. Soy consciente de que la СРв no solamente afirma el pluralismo jurídico sino también el jurisdiccional, y es trascendental identificar, a nivel social y jurídico, qué entendemos por pluralismo jurídico y, sobre todo, por pluralismo jurisdiccional. Reconocer una justicia diferente y paralela a la estatal significa en definitiva romper con el monismo jurídico que identifica el derecho con el Estado. En este sentido el pluralismo jurídico y jurisdiccional "cuestiona

17 Ver Pascucci de Ponte, E. La escuela europea del derecho natural. En Saberes. Revista de estudios jurídicos, económicos y sociales, vol. 1, 2003, 18.

18 Tratado ratificado por Bolivia el 12 de agosto de 1982.

19 En este sentido ver GARGARELLA, R. Apuntes sobre el constitucionalismo latinoamericano del siglo XIX. Una mirada histórica. En Revista del Instituto de Ciencias Jurídicas de Puebla (nueva época), año IV , n. ${ }^{\circ} 25,2010,37$.

20 Entre otros ver Rivera, J. A., El nuevo sistema constitucional boliviano. En Revista Peruana de Derecho Público, año 10, n. ${ }^{\circ}$ 18, enero-julio, 2009, 74. 
aquella concepción monista que ha reducido la diversidad endémica de la sociedad a una sola visión dominante del derecho" ${ }^{21}$.

Tras esto, a nivel práctico, parece bastante clara la apertura del monismo jurídico al pluralismo jurídico, mientras que diferente parece el alcance del pluralismo jurisdiccional. En este sentido compartimos la primera parte de la definición otorgada por Sánchez Castañeda: "el pluralismo jurisdiccional es la posibilidad de que en un mismo momento coexistan varios sistemas jurídicos, lo que supone un pluralismo de sistemas" ${ }^{22}$. No puedo compartir la segunda parte de la definición cuando el autor identifica "un pluralismo de sistemas pero no una pluralidad de mecanismos o de normas jurídicas" 23 .

En mi visión es necesario que a un sistema jurídico le corresponda un conjunto de normas, es decir, las normas jurídicas representan la herramienta técnico-legal que teje el sistema jurídico sin el cual el complejo de las normas sería demasiado empírico. En este modelo negamos un pluralismo jurídico sin un pluralismo jurisdiccional. En otras palabras, sí existe una diferencia sustancial entre pluralismo jurídico y jurisdiccional. Si por un lado, entonces, como afirma Yrigoyen Fajardo, "[1]a perspectiva teórica del pluralismo jurídico permite y reconoce que dentro de un mismo espacio geopolítico (estado) pueden coexistir varios sistemas jurídicos además del estatal. Los sistemas normativos indígenas son sistemas jurídicos o derecho: tienen capacidad para crear normas, resolver conflictos, organizar el orden" ${ }^{24}$, por el otro, la misma CPB reconoce un sistema de autoridades con funciones jurisdiccionales y de competencias a través de sus autoridades ${ }^{25}$.

La misma СРB en el artículo 30.II.14 reconoce a los pueblos indígenas originarios campesinos el derecho "al ejercicio de sus sistemas políticos, jurídicos y económicos acorde a su cosmovisión". Se reconoce finalmente la autorregulación dentro de su sistema jurídico. Según esta perspectiva, el pluralismo jurídico es el reconocimiento de diferentes sistemas jurídicos que debiendo convivir permiten, a través de sus normas y costumbres, reglamentar a los individuos evitando que un sistema prevalezca sobre el otro. Para alcanzar este objetivo es necesario replantear el concepto de justicia, es esencial establecer si la justicia "occidental" es el único modo de gestionar los conflictos, y, sobre todo, intentar comprender la posibilidad de que no solamente el Estado tenga reconocida la acción de coacción sobre el pueblo.

21 Garzón LóPez, P. Pluralismo jurídico. Eunomía. En Revista en Cultura de la Legalidad, n. ${ }^{\circ}$ 5, septiembre de 2013-febrero de 2014, 186.

22 Sánchez Castañeda, A. Los orígenes del pluralismo jurídico. En Alba O. S. y Castro S. R. Pluralismo jurídico e interculturalidad. Instituto de Estudios Internacionales de Bolivia, Asamblea Constituyente Boliviana, 22.

23 Ibíd.

24 Yrigoyen Fajardo, R. Pautas de coordinación entre el derecho indígena y el derecho estatal. Guatemala: Fundación Myrna Mack, 1999, 14.

25 Ver, p. ej., art. 191.II.2. 
Aunque teóricamente sepamos que no es así, a nivel práctico la justicia ordinaria sigue siendo la "buena justicia", mientras que la indígena resulta ser la salvaje, por lo menos a los ojos de la ciudadanía no indígena. Esta afirmación radica en principios que quizá van más allá de meras cuestiones jurídicas. Lo anterior, si nos remontamos al año 2007 y en particular al periodo de sesión de la Asamblea Constituyente, a instancias del Comité Interinstitucional, conformado por grupos regionales cívicos, empresariales, prefecturales y municipales, al igual que en los departamentos de Santa Cruz, Beni, Pando y Tarija, que representaban y defendían intereses sectoriales concretos con acción y movilización opositora, la mayor de las veces transgrediendo derechos de los sectores sociales más vulnerados, como de las naciones y pueblos indígenas originarios y campesinos. Los planteamientos de estos grupos en torno a su movilización radicaban en las autonomías departamentales en el marco de su sistema cuasi-federal, en mantener el latifundio agrario y las agroindustrias, como base del modelo de producción y económico en las regiones, pero también para mantener el corte de un Estado liberal y monocultural, con el fin de defender sus intereses sectoriales ${ }^{26}$.

Se trata finalmente de un tipo de globalización que no solo uniformiza nuestras vidas sino que estandariza los sistemas jurídicos; sin embargo y en los que a nosotros nos atañe, las diferencias jurídicas deberían servir para fortalecer la unión de los pueblos que habitan el mismo territorio. No admitir esto significa elegir entre un mundo y otro ${ }^{27}$.

En este contexto, los puntos que más me preocupan son: a) el concepto de multiculturalismo boliviano útil para comprender el arraigo jurídico y social del indigenismo boliviano, y b) la coexistencia de diferentes sistemas jurídicos así como la compatibilidad entre sistemas jurisdiccionales. En relación con el primero, explica Velasco Gómez que las demandas multiculturalitas son muy diversas. Pueden vincularse con cuestiones religiosas o políticas, luchar por la preservación ecológica o la posesión o uso de territorios, o bien demandar la impartición de justicia de acuerdo con usos y costumbres de comunidades específicas. En todo caso, las demandas multiculturalitas se refieren fundamentalmente al reconocimiento de identidades, prácticas, instituciones y derechos de grupos minoritarios frente a una cultura "nacional" dominante y "homogeneizante", promovida y muchas veces impuesta

26 En este sentido, entre otros, ver Bascopé SAnjínes, I. Consulta previa: reto de democracia comunitaria. En De Sousa Santos, B. y Exeno Rodríguez, J. L., eds. Justicia indígena, plurinacionalidad e interculturalidad en Bolivia, Quito: Ediciones Abya Yala, Fundación Rosa Luxemburg, 2012, 383.

27 Entre otros, ver HARRIS, L. La justicia como modo de supervivencia de una comunidad. En AA.vv. Justicia en las comunidades indígenas. Contribución al debate sobre pluralismo jurídico y sistemas de justicia en Bolivia. Enlace Consultores en Desarrollo, Embajada de los Estados Unidos, 2005, 31. 
desde el poder del Estado ${ }^{28}$. Cabe a tal propósito evidenciar el artículo 5.I СРB en materia de territorio, lengua y pueblos. La Constitución recoge 36 diferentes nacionalidades y pueblos indígenas originarios campesinos; sin embargo, tras una breve investigación hemos podido hacer un listado de 181 comunidades, aunque por comunidades como los Quechuas o los Aymaras es imposible calcular fielmente todas las diversidade ${ }^{29}$. Finalmente el alcance de la nueva Constitución no podía ser diferente. La ley indígena se asienta en características muy peculiares: "el derecho indígena se fundamenta en una filosofía o religión de la dualidad armónica: así como el sol (hombre-padre) y la luna (mujer-madre) se complementan y se unen, sin perder su diferencia y particularidad. Estos principios de equilibrio, interrelación y armonía entre hombre, naturaleza y sociedad se aplican también en las relaciones sociales"30. La autoridad indígena es la encargada de solventar los conflictos y actúa, en primera instancia, como si fuera un árbitro y no tanto como un juez.

Es cierto entonces que la СРв ha conseguido establecer un respetable nivel de distribución entre juez ordinario y justicia comunitaria. Al respecto, Clavero señala:

Tengamos presente que el derecho internacional de derechos indígenas es parte integrante del derecho internacional de derechos humanos, una parte necesaria porque, con las fuertes secuelas del colonialismo, el racismo y el supremacis$m o$, la humanidad indígena viene sufriendo discriminación y hasta exclusión en el beneficio de los derechos. Por esto se ha hecho necesaria la Declaración de Naciones Unidas sobre los Derechos de los Pueblos Indígenas, una declaración que, si les distingue, es para cancelar su discriminación. Ecuador y Bolivia son los primeros Estados en responder constitucionalmente a la Declaración sobre los Derechos de los Pueblos Indígenas. Haciéndolo a su letra y a su espíritu, establecen un sistema ya dispuesto a reconocer y capaz de garantizar los derechos humanos y las libertades fundamentales en un pie efectivo de igualdad ${ }^{31}$.

En definitiva, no es tan fácil comprender la relación entre la justicia ordinaria y los límites, si existen, de la justicia indígena originaria campesina. Como he tenido la oportunidad de mencionar en otras ocasiones, creo importante

28 Velasco Gómez, A. Multiculturalismo, nación y federalismo. En Revista Mexicana de Ciencias Políticas y Sociales, vol. 47, n. ${ }^{\circ}$ 191, 2004, 87.

29 Ver: www.amazonia.bo/pueblos.php?opcion=pueblos\&codigo=5. Este sitio de internet es una compilación de las comunidades incluidas en la división entre Amazonia, Chaco y Andes.

30 BARIÉ, C. G. Derechos indígenas y medios alternativos de resolución de conflictos. En Revista Latinoamericana de Seguridad Ciudadana, n. ${ }^{\circ}$ 3, enero, 2002, 113.

31 Clavero, B. Ecuador y Bolivia: Nuevas constituciones y derecho internacional de derechos indígenas. Miembro del Foro Permanente de Naciones Unidas para las Cuestiones Indígenas, disponible en: www.clavero.derechosindigenas.org/?p=750 
reportar en esta sede dos ejemplos que entre otros resumen la relación entre dos maneras distintas de entender la justicia.

[1.] Año 1976, comunidad Cahuayo, provincia Frías del departamento de Potosí, frontera con Oruro. Una mujer casada incurrió en adulterio[,] su madre insta a la convocatoria y realización de una asamblea de la comunidad, la que tiene lugar pocos días después de descubierta la relación extra matrimonial. La comunidad delibera, llega a la conclusión de que la falta es muy grave y resuelve imponerle la pena de muerte como sanción. El marido engañado recibe, de mano de su suegra, un revólver y la instrucción de matar a la mujer, dispara sobre su esposa pero no la mata, luego el hermano de la mujer hace lo propio, sin matarla tampoco. Por último, el Corregidor Auxiliar, en nombre de la ley comunitaria, ejecuta el disparo fatal y mata a la mujer. Las autoridades del Estado, conocedoras del caso por denuncia de una persona, proceden a la aprehensión del esposo y el hermano, en tanto el Corregidor y la madre se fugan del lugar. Se realiza un proceso en el Juzgado de Partido Primero en lo Penal de la ciudad de Potosí, donde se condena a los mencionados a la pena de diez años de presidio.

[2.] Año 1993, comunidad Siporo, Provincia Cornelio Saavedra del departamento de Potosí. Un comunitario violó a una niñita de tres años[,] no era la primera vez que actuaba de este modo. Luego de hacerlo, el autor desapareció del lugar por algún tiempo, retornando al cabo de unos meses a la comunidad. Cuando se produjo el retorno, su hermano dio el aviso a los comunitarios acerca de la llegada del violador[,] se realizó una reunión en la cual se decidió quitar la vida al autor del delito. Se procedió de inmediato. Hasta el día de hoy, la policía ni siquiera llegó al lugar y quienes participaron del acto guardan silencio en relación con el caso ${ }^{32}$.

En las comunidades indígenas la justicia no responde al principio retributivo de la pena. Por ejemplo, en materia de divorcio el testimonio de la Autoridad Originaria de Jach'a Karangas relata:

El divorcio es una figura reciente, la esposa sigue siendo la esposa de una persona hasta su muerte, la otra persona que tal vez tendrá otra catalogación, solamente se queda en eso, la comunidad sigue reconociéndola a esa persona como la esposa pese a que ya no vive con esa persona, si esa persona ha salido, porque generalmente ese es el caso, les dejan en la comunidad y se van a las ciudades y va a convivir con otra persona, pero la comunidad en tanto y cuanto esa persona viva la reconoce como esposa y la continúa acogiendo en los terrenos de esa persona y continúan los hijos usufructuando de los terrenos del padre ${ }^{33}$.

32 AA.Vv. Sobre el pluralismo jurídico. Documento de trabajo 13. Serie: Autonomías en la Constitución. Instituto Internacional para la Democracia y la Asistencia Electoral, 2009, 17.

33 Fuente: testimonio de Autoridad Originaria de Jach'a Karangas, en la Mesa de Trabajo del Sistema de Justicia, realizada en Oruro, 17 de abril de 2010. 
Se trata de algunos ejemplos en donde los comunitarios se entregan totalmente a la comunidad, que finalmente se convierte en el patrimonio más importante (madre-hija, hombre-hermano). El conflicto entre personas genera un desequilibrio, una ruptura de las relaciones y la comunidad entonces, a través de la justicia indígena, intenta no tanto reparar el delito sino más bien restablecer la armonía perdida. La autoridad indígena concilia y media basando su actividad en la satisfacción de características como la honestidad, la sabiduría, la legitimidad y el reconocimiento moral. De igual forma, la autoridad indígena debe poseer cualidades y habilidades sociales y técnicas que permitan la reconciliación. Bajo la guía suprema de la Autoridad indígena, el culpable asume su responsabilidad y su culpa, admite la verdad (se obliga a no mentir, ama llulla) y reintegra el daño, resultando de esta manera completamente rehabilitado. Como he dicho con anterioridad, se restablece la armonía entre el demandante y el autor del delito o del daño. Entendemos entonces que la pena tiene unos rasgos diferentes de los que asume el derecho penal positivo. La pena debe castigar y en algunos casos servir de reinserción social, pero nunca se entiende como reparación a los dañados. Si el Estado, mediante su poder de coacción hace respetar las normas, la justicia indígena tiene raíces más profundas, filosóficas y espirituales. Si la comunidad no vive en armonía, los dioses se rebelarán y esto podría crear una descompensación social incontrolable.

\section{LA LÍNEA DE DEMARCACIÓN DE LOS LÍMITES DE LA JUSTICIA INDÍGENA}

En todo esto me parece interesante establecer si hay o no una línea insuperable que la justicia indígena no puede y no debe superar. La respuesta sencilla pasa por dos vertientes. La primera representada por el respeto de los derechos humanos y la segunda por los límites impuestos por la misma Constitución. Si aceptara las dos visiones, a mi parecer, estaría haciendo colonialismo jurídico. No podemos olvidar que los derechos humanos así como los derechos constitucionales son el producto de la visión positiva del derecho. No se trata de desconocer el derecho positivo, yo mismo soy el producto académico de este enfoque, sin embargo no quiero cometer el error de posicionar la justicia indígena por debajo de otras fuentes del derecho. Cuando se habla de justicia indígena nos referimos a cuestiones ancestrales, espirituales, culturales que no se guían por los mismos criterios a los que nos han acostumbrado y sobre los cuales nos formaron. La justicia indígena no se aplica a todos y todas aquellos y aquellas que tienen rasgos diferentes del hombre "blanco" o del hombre "negro". El Convenio 169 de la oIT considera a una persona como indígena "por el hecho de descender de poblaciones que habitaban en el país, o en una región geografía a la que pertenece el país y [...] que conservan sus instituciones sociales, económicas, culturales y políticas o parte de ellas". Se 
trata, dice el Convenio 169, de pueblos que conservan "sus sistemas legales" ${ }^{34}$. Es decir, se anteponen sus sistemas legales a cualquier otro sistema, y en otras palabras, hay tantos sistemas como pueblos indígenas.

Ninguno de ellos sobresale sobre otro y ninguno de ellos es inferior a otro. Si se reconocen los pueblos indígenas así como hemos descrito, es necesario detenernos frente a la aplicación de su justicia también cuando el ejercicio de esta difiere totalmente de los cánones occidentales. Sólo de esta manera dejaremos de ver la justicia indígena como escasamente moral y limitadora de los derechos que nosotros mismos nos hemos autoimpuesto.

\section{A MODO DE CONCLUSIÓN}

Debemos reconocer que la semántica sigue dominando el terreno jurídico. Lo que acabamos de describir sin duda puede tener una doble lectura. Si por un lado genera problemas la utilización de conceptos como neoconstitucionalismo o pluralismo jurídico, por el otro es necesario esclarecer su significado y su alcance. Entendemos que la interpretación filológica de estos términos es diferente de la que puede otorgar un jurista. El neoconstitucionalismo no puede entonces representar la "terapia" que elimina todas las enfermedades del constitucionalismo que finalmente se ve alienado de los principios económicos y capitalistas.

El nuevo y más completo abanico de derechos incluidos en la Constitución Política de Bolivia de 2009 es un reto, es un desafío sin embargo que choca con el necesario reconocimiento del principio de efectividad. Una constitución no puede o no debería depender de la lógica política de un determinado poder o partido político, así que el concepto de política debería quedarse cuanto más posible apartado del contenido de la constitución. El problema es que la constitución se identifique como un programa gubernamental, perdiendo entonces aquel carácter de abstracción necesario para que con los años la ley fundamental pueda adaptarse a los cambios sociales sin que esto afecte al chasís de la misma carta. Es obligación estatal hacer cumplir lo que la constitución dicta. Si esto no ocurre, las normas constitucionales pierden cualquier contenido mínimo.

Es muy interesante la apertura al pluralismo jurídico y jurisdiccional, sin embargo, para entender el verdadero alcance de la justicia indígena es

34 Somos conscientes de que el Convenio 169 de la orT en esta materia resulta tajante: los artículos 8.2 y 9.1 anteponen los derechos humanos al derecho indígena originario campesino cuando este se extralimite en materia de derechos humanos. De la misma manera, el artículo 190.2 СРв indica: "La jurisdicción indígena originaria campesina respeta el derecho a la vida, el derecho a la defensa y demás derechos y garantías establecidos en la presente Constitución". Sin embargo, parece que en la redacción de estas normas prevalece la visión positiva del derecho, allí donde la justicia indígena se mueve sobre la base de costumbres ancestrales que no responden a los principios positivistas del derecho. 
necesario hacer una operación de vaciamiento de nuestros prejuicios, liberar nuestra mente de las lógicas occidentales y favorecer la comprensión de aquellas dinámicas "diferentes" y que en algunas puntuales ocasiones llegan a discrepar totalmente de nuestra visión del derecho.

Este finalmente es el verdadero desafío del que la ciudadanía debe tomar conciencia.

\section{REFERENCIAS}

AA.vv. (2009). Sobre el pluralismo jurídico. Documento de trabajo 13. Serie: Autonomías en la Constitución. Instituto Internacional para la Democracia y la Asistencia Electoral.

Alvarado, A. (1994). Del constitucionalismo liberal al constitucionalismo social. Teoría y práctica. Sucre: Corte Suprema de Justicia de la Nación, Editorial Judicial.

Attard Bellido, M. E. (2012). La última generación del constitucionalismo: el pluralismo descolonizador intercultural y sus alcances en el Estado Plurinacional de Bolivia. Revista Lex Social. Vol. 2, n. ${ }^{\circ}$, julio-diciembre.

BARIÉ, C. G. (2002). Derechos indígenas y medios alternativos de resolución de conflictos. Revista Latinoamericana de Seguridad Ciudadana, n. ${ }^{\circ}$, enero.

BArié, C. G. Derecho indígena y medios alternativos de resolución de conflictos. Urvio. Revista Latinoamericana de Seguridad Ciudadana, n. . 3, Flacso, 2008.

Bascopé Sanjínes, I. (2012). Consulta previa: reto de democracia comunitaria. En De Sousa Santos, B. y Exeno Rodríguez, J. L., eds. Justicia indígena, plurinacionalidad e interculturalidad en Bolivia. Quito: Ediciones Abya Yala, Fundación Rosa Luxemburg.

Carbonell Sánchez, M. (2007). El neoconstitucionalismo en su laberinto. Teoría del neoconstitucionalismo: ensayos escogidos.

De Vega García, P. (1998). Mundialización y derecho constitucional: la crisis del principio democrático en el constitucionalismo actual. Revista de Estudios Políticos (nueva época), n. ${ }^{\circ} 100$, abril-junio.

Díaz Gamboa, L. B. (2001). Constitucionalismo social: hacia un nuevo Estado social, democrático de derecho. Instituto Sindical Mario Cano.

Dippel, H. (2005). Constitucionalismo moderno: una historia que necesita ser escrita. Revista Electrónica de Historia Constitucional, n. ${ }^{\circ}$ 6, septiembre.

Fioravanti, M. (2014). Constitucionalismo. Experiencias históricas y tendencias actuales. Editorial Trotta.

Gargarella, R. (2010). Apuntes sobre el constitucionalismo latinoamericano del siglo XIX. Una mirada histórica. Revista del Instituto de Ciencias Jurídicas de Puebla (nueva época), año IV, n. ${ }^{\circ} 25$.

Garzón López, P. (2014). Pluralismo jurídico. Eunomía. Revista en Cultura de la Legalidad, n. ${ }^{\circ}$ 5, septiembre 2013-febrero 2014. 
HARris, L. (2005). La justicia como modo de supervivencia de una comunidad. En AA.vv. Justicia en las comunidades indígenas. Contribución al debate sobre pluralismo jurídico y sistemas de justicia en Bolivia. Enlace Consultores en Desarrollo, Embajada de los Estados Unidos.

Herreros López, J. M. (2011). La justiciabilidad de los Derechos Sociales, Lex SocialRevista de los Derechos Sociales núm. 1, julio-diciembre.

Kats, C. (2014). La sorpresa de Bolivia. Nómadas. Revista Critica de Ciencias Sociales y Jurídicas, n. $^{\circ} 44$.

Noguera Fernández, A. (2010). ¿De qué hablamos cuando hablamos de constitucionalismo multicultural? Anuario de la Facultad de Derecho, vol. XVIII.

Pascucci De Ponte, E. (2003). La escuela europea del derecho natural. Saberes. Revista de estudios jurídicos, económicos y sociales, vol. 1.

Pizzorusso, A. (2002). Il patrimonio costituzionale europeo. Il Mulino.

Ratti, G. B. (2015). Neoconstitucionalismo positivo y neoconstitucionalismo negativo. Ius Humani. Revista de Derecho, vol. 4, 2014/2015.

Rivera, J. A. (2009). El nuevo sistema constitucional boliviano. Revista Peruana de Derecho Público, año 10, n. $^{\circ} 18$, enero-julio.

Sánchez Castañeda, A. Los orígenes del pluralismo jurídico. En Alba, O. S. y Castro, S. R. Pluralismo jurídico e interculturalidad. Instituto de Estudios Internacionales Bolivia, Asamblea Constituyente Boliviana.

Valencia Vega, A. (2002). Desarrollo del constitucionalismo. Colección Ayer y Hoy. La Paz: Juventud.

Velasco Gómez, A. (2004). Multiculturalismo, nación y federalismo. Revista Mexicana de Ciencias Políticas y Sociales, vol. 47, n. ${ }^{\circ} 191$.

Viciano Pastor, R. (2008). Una análisis sobre la propuesta de reforma constitucional de Venezuela en 2007. Cuadernos de Trabajos Hengoa, n. 44.

Villabella Armengol, C. M. (2010). Constitución y democracia en el nuevo constitucionalismo latinoamericano. Revista del Instituto de Ciencias Jurídicas de Puebla (nueva época), año IV, . $^{\circ} 25$, verano.

Yrigoyen Fajardo, R. (1999). Pautas de coordinación entre el derecho indígena y el derecho estatal. Guatemala: Fundación Myrna Mack.

Zagrebelsky, G. (2002). Il diritto mitte. Legge, diritti, giustizia. Torino: Einaudi, 1992; trad. esp., El derecho dúctil, Marina Gascón, trad. Madrid: Trotta, 4. ${ }^{\text {a }}$ ed.

\section{Bibliografía en línea y páginas web}

Comunidades indígenas originarios campesinas, www.amazonia.bo/pueblos. php?opcion $=$ pueblos\&codigo $=5$ (Consulta 28 de mayo de 2015). 
Clavero, B. Ecuador y Bolivia: Nuevas constituciones y Derecho Internacional de Derechos Indígenas. Miembro del Foro Permanente de Naciones Unidas para las Cuestiones Indígenas, disponible en: www.clavero.derechosindigenas.org/?p=750

Rolla, G. L'evoluzione del costituzionalismo in America Latina e l'originalità delle esperienze di giustizia costituzionale, disponible en: http://ojs.uniurb.it/index.php/studi-A/ article/download/109/101 